\title{
Mechanical and Magnetocaloric Properties the Composite Based on PMMA and Gd-Ge-Si as Reinforcement
}

\author{
Felipe Mello Rigon ${ }^{a}$, Andressa dos Santos ${ }^{a}$, Jean Halison de Oliveira ${ }^{b}$, Laís Weber Aguiar ${ }^{a}(\mathbb{0}$, \\ Wagner André dos Santos Conceição ${ }^{a}$, Paulo Vinicius Trevizolia,c, Silvia Luciana Favaro ${ }^{a *}$, \\ Cleber Santiago Alves ${ }^{a}$
}

\author{
${ }^{a}$ Universidade Estadual de Maringá (UEM), Departamento de Engenharia Mecânica (DEM-PEM), \\ CEP 87020-900, Maringá, PR, Brasil \\ ${ }^{b}$ Universidade Estadual de Maringá (UEM), Departamento de Química (DQI-PQU), CEP 87020-900, \\ Maringá, PR, Brasil \\ ${ }^{c}$ Universidade Federal de Minas Gerais (UFMG), Departamento de Engenharia Mecânica DEMEC, \\ CEP 31270-901, Belo Horizonte, MG, Brasil
}

Received: September 01, 2020; Revised: April 06, 2021; Accepted: April 27, 2021

\begin{abstract}
This research work investigates a new type of polymer-based magnetocaloric composite. Using PMMA as polymeric matrix and the magnetocaloric material $\mathrm{Gd}_{5.09} \mathrm{Ge}_{2.03} \mathrm{Si}_{1.88}$ as reinforcement,no influence of the presence of polymer on the magnetic properties of $\mathrm{Gd}_{5.09} \mathrm{Ge}_{2.03} \mathrm{Si}_{1.88}$ were observed. Three types of composites with different PMMA content were fabricated by mixing the components and curing the composite. The composites were evaluated by their mechanical, physicochemical and morphological properties. The proposed PMMA composite MC10 presented the smallest elastic modulus but highest Vickers hardness (6.61 $\pm 0.08 \mathrm{GPa}$ and $22.10 \pm 1.29 \mathrm{HV}$, respectively). The composites showed asatisfactorymagnetocaloriceffect (MCE)"peak" of $-7 \mathrm{~J} / \mathrm{kgK}$. With the results, this composite can be a potential candidate for applications as Active Magnetic Regenerator in magnetic heat pumps.
\end{abstract}

Keywords: Magnetocaloric effect, PMMA composite, magnetic refrigeration, Active Magnetic Regenerator.

\section{Introduction}

After the discovery of the giant magnetocaloric effect (GMCE) in the $\mathrm{Gd}_{5} \mathrm{Ge}_{2} \mathrm{Si}_{2}$ alloy by Pecharsky and Gschneidnerin ${ }^{1,2}$, interest and research about magnetic heat pumps increased significantly, resulting in the development of novel magnetocaloric materials and prototypes ${ }^{3-6} \cdot \mathrm{Gd}_{5} \mathrm{Ge}_{2} \mathrm{Si}_{2}$ is a first-order magnetocaloric material, which does not show the GMCE before heat treatment is performed ${ }^{1,2}$. In later studies, Pires et al. ${ }^{7}$, Franco et al. ${ }^{8}$, Grego et al. ${ }^{9}$ observed that a slightly different stoichiometry, $\mathrm{Gd}_{5.09} \mathrm{Ge}_{2.03} \mathrm{Si}_{1.88}$, as-cast compound shows GMCE without heat-treatment. One of the main advantages of materials based on the magnetocaloric effect (MCE) is its potential application in solid-state magnetic cooling, since most refrigeration technology relies on the conventional gas compression technique, which has drawn increasing criticisms due to its lack of efficiency and use of air-pollutant gases ${ }^{7-9}$. Systems based on the MCE are expected to replace the traditional gas compression refrigerant system due to their environmental friendly aspect and higher conversion efficiency aside the possibility of small and large scale applications ${ }^{10-12}$.

For the $\mathrm{Gd}_{5.09} \mathrm{Ge}_{2.03} \mathrm{Si}_{1.88}$ as-cast compound be applied as highly efficient active magnetic regenerator (AMR) $)^{13,14}$, it is necessary to manufacture this compound in a given

*e-mail: slfrosa@uem.br geometry, such as plates, pins, microchannels or spherical particles, which should guarantee good heat transfer properties associated with low viscous losses ${ }^{15,16}$. However, $\mathrm{Gd}_{5.09} \mathrm{Ge}_{2.03} \mathrm{Si}_{1.88}$ mechanical properties are not adequate to allow conventional manufacturing process. For instance, this alloy is very brittle and fragile, and previous works reported that conventional manufacturing processes such as powder metallurgy could reduce its $\mathrm{GMCE}^{17}$. This way, manufacturing this alloy as a composite material may be a promising alternative to finally use $\mathrm{Gd}_{5.09} \mathrm{Ge}_{2.03} \mathrm{Si}_{1.88}$ as AMRs, as well as other promising first-order material (which also present the GMCE $)^{1,18}$.

The use of magnetocaloric-based composites has been already proposed in the literature. Some of them use structural composites ${ }^{19,20}$, while others betake epoxy resins to give structural integrity to the material ${ }^{21-24}$. Lanzarini et al. ${ }^{25}$, Lazouzi et al. ${ }^{26}$, Chen et al. ${ }^{27}$, Liu et al. ${ }^{28}$ presented the prepare of a La-Fe-Si/ $\mathrm{Cu}$ composite and its mechanical and MCE behavior at hot pressing tests. So far, the works published by Pecharsky and Gschneidner ${ }^{29}$, Pecharsky et al. ${ }^{30}$ Imamura et al. ${ }^{31}$ and Zhang et al. ${ }^{32}$ have reported magnetocaloric and mechanical properties for different types of composites.

The present paper reports and discusses the mechanical and magnetic properties of a magnetocaloric composite, which was processed with a polymer matrix based on poly(methyl methacrylate) (PMMA) and $\mathrm{Gd}_{5.09} \mathrm{Ge}_{2.03} \mathrm{Si}_{1.88}$ magnetocaloric 
alloy as reinforcement. The experimentally characterized mechanical properties are the elastic modulus and Vickers hardness. Magnetization as function of temperature are also presented. Finally, the isothermal entropy variation for the composite, which is a characterization of the MCE, is presented and compared with the as-cast alloy.

\section{Experimental}

\subsection{Magnetocaloric reinforcement $G d_{5.09} G e_{2.03} S i_{1.88}$}

$\mathrm{Gd}_{5.09} \mathrm{Ge}_{2.03} \mathrm{Si}_{1.88}$ samples were prepared by arc melting furnace under argon atmosphere $(99.99 \mathrm{wt} \%$, Linde) following the procedure described by Pecharsky and Gschneidner ${ }^{29}$, Pecharsky et al. ${ }^{30}$, Imamura et al. ${ }^{31}$ using an adapted setup mainly consisted by a vacuum pump (E2M18, Edwards), a stainless steel cylindrical fusion chamber, a tungsten electrode with diameter of $4 \mathrm{~mm}$, a hollowed copper crucible, a power supply (DALEXWERK, Niepenberg\& Co), manometers from Zürich and Edwards and three stainless steel storage chambers for store raw and sample materials under an argon atmosphere. To guarantee the homogeneity, each sample was re-melted at least twice. The basic constituents have the purities of $99.90 \mathrm{wt} \%$ for Gd, $99.99 w t \%$ for Ge and $99.95 w t \%$ for Si. A total of 21 bulk samples, with approximately $5 \mathrm{~g}$ each, manually milled and mixed to obtain a homogeneous base-powder, and then the particles ranging from 38 to $45 \mu \mathrm{m}$ were sieved and selected.

\subsection{Magnetocaloric composite: Acrylic Resin/ $G d_{5.09} G e_{2.03} S i_{1.88}$}

The composite samples were manufactured initially mixing the $\mathrm{Gd}_{5.09} \mathrm{Ge}_{2.03} \mathrm{Si}_{1.88}$ powder with poly(methyl methacrylate) (PMMA) and dibenzoyl peroxide (DBP) powder using a mortar and pestle, in the proportions of PMMA of 5, 7 and $10 \mathrm{wt} \%$, as in Table 1. Concentrations lower than $5 \mathrm{wt} \%$ make composites too brittle and fragile, not being used in the study. Using an aluminum mold, the mixture was shaped in discs of $25 \mathrm{~mm}$ diameter and $1 \mathrm{~mm}$ thickness. The methyl methacrylate (MMA) with redox system of initiator dimethylparatoluidine (DMPT) was added until the powder mixture was completely wet. The mixture was left to cure with low pressure applied. All the samples were manufactured in duplicate, and two control samples were made without $\mathrm{Gd}_{5.09} \mathrm{Ge}_{2.03} \mathrm{Si}_{1.88}$ reinforcement (pure PMMA).

\subsection{Experimental characterization}

The samples were characterized by Attenuated Total Reflectance with Fourier Transform Infrared -ATR-FTIR (Nicolet iZ10 model, Thermo Fisher Scientific, Madison, WI, USA) equipped with SMART-ITR-ATR ZnSe crystal, with a resolution of $4 \mathrm{~cm}^{-1}, 64$ scans and frequencies between 2000 and $650 \mathrm{~cm}^{-1}$. The MMA sample was analyzed using $\mathrm{NaCl}$ plates for FTIR (SMART OMNI-TRANSMISSION) under the same parameters.

Thermogravimetric analysis (TGA) was carried out using a STA6000 (PerkinElmer, Waltham, MA, USA), under nitrogen gas atmosphere $(20 \mathrm{~mL} / \mathrm{min})$ with a heating rate of $10{ }^{\circ} \mathrm{C} / \mathrm{min}$ from 50 to $900{ }^{\circ} \mathrm{C}$.

The samples were also examinned via Scanning Electron Microscopy - SEM (Quanta 250, FEI, Hilsboro, OR, USA). To preserve the structure of the polymer matrix, the samples were fractured after cooled with liquid nitrogen.

\subsection{Mechanical properties}

Surface microhardness of magnetocaloric composites was measured using a Vickers diamond indenter (HVS-5, Weiyi, Shandong, China), applying a load of $300 \mathrm{~g}$ and dwelling time of $30 \mathrm{~s}$. The elastic modulus of magnetocaloric composites was determined using Poisson's ratio by impulse excitation of vibration technique (ASTM E1876-09) ${ }^{33}$.

\subsection{Magnetic measurements}

Magnetic measurements of the $\mathrm{Gd}_{5.09} \mathrm{Ge}_{2.03} \mathrm{Si}_{1.88}$ powder were performed using a commercial superconducting quantum interference device (SQUID) from Quantum Design ${ }^{29-31}$. Magnetization curves ( $M$ vs. T) were measured with a fixed magnetic field of $100 \mathrm{Oe}$, increasing the temperature at the rate of $2 \mathrm{~K} / \mathrm{min}$, from $220 \mathrm{~K}$ to $350 \mathrm{~K}$. From a numeric differentiation of the magnetization data, we calculated the temperatures of the first- and second-order transitions by a local minimum at $\mathrm{dM} / \mathrm{dT}$ vs. T curves. The isothermal magnetization curves ( $\mathrm{M}$ vs. $\mathrm{H}$ ) were measured at different isotherms ranging from $200 \mathrm{~K}$ to $350 \mathrm{~K}$ with steps of $2 \mathrm{~K}$. The applied magnetic fields ranged from 0 to $20 \mathrm{kOe}$ with steps of $2 \mathrm{kOe}$. From the isothermal magnetization data, we calculated the isothermal entropy variation $\left(\Delta \mathrm{S}_{\mathrm{T}}\right)$, which is a parameter that represents the magnetocaloric effect, by numeric approximation,

Table 1. Composition, mass and dimension of composite samples.

\begin{tabular}{cccccc}
\hline Sample & $\begin{array}{c}\mathrm{Gd}_{5.09} \mathrm{Ge}_{2.03} \mathrm{Si}_{1.88} \\
(\mathrm{wt} \%)\end{array}$ & PMMA (wt\%) & Mass (g) & Diameter (mm) & Thickness (mm) \\
\hline MC5_1 & 95 & 5 & 1.925 & 24.88 & 1.15 \\
\hline MC5_2 & 95 & 5 & 1.847 & 24.72 & 1.20 \\
\hline MC7_1 & 93 & 7 & 1.910 & 24.97 & 1.25 \\
\hline MC7_2 & 93 & 7 & 1.686 & 24.92 & 1.20 \\
\hline MC10_1 & 90 & 10 & 1.677 & 25.00 & 1.10 \\
\hline MC10_2 & 90 & 10 & 0.683 & 25.00 & 1.25 \\
\hline Control_1 & 0 & 100 & 0.571 & 25.00 & 1.15 \\
\hline Control_2 & 0 & 100 & &
\end{tabular}

$\mathrm{MC}=$ Magnetocaloric composite. The numbers after MC show composition whereas the numbers 1 and 2 are the duplicates. 
$\Delta S_{T}(T)_{\Delta H}=\frac{1}{2 \delta T}\left(\delta M_{1} \delta H_{1}+2 \sum_{k=2}^{n-1} \delta M_{k} \delta H_{k}+\delta M_{n} \delta H_{n}\right)$

As already discussed in the literature ${ }^{29-31}$, the magnetocaloric composites were characterized following the same experimental procedure and by using the same device.

\subsection{Statistical analysis}

To investigate the statistical influence of the $\mathrm{Gd}_{5.09} \mathrm{Ge}_{2.03} \mathrm{Si}_{1.88}$ as-cast compound into the mechanical properties of the composites, the Analysis of Variance (ANOVA) of one factor was used, followed by Tukey's test evaluated under significance level of $5 \%$.

\section{Results and Discussion}

\subsection{FTIR}

The FTIR spectra of the acrylic resin components (MMA and PMMA), control and the $\mathrm{Gd}_{5.09} \mathrm{Ge}_{2.03} \mathrm{Si}_{1.88}$ as-cast compound dispersed in acrylic resin, in different amounts, are shown in Figure 1. The band at $1730 \mathrm{~cm}^{-1}$ is associated with $\mathrm{C}=\mathrm{O}$ stretching characteristic of acyl group derived from acrylic acid and can be observed in all spectra ${ }^{34}$. The $\mathrm{C}=\mathrm{C}$ stretching was detected at $1650 \mathrm{~cm}^{-1}$ in the spectra MMA from acrylic $\operatorname{acid}^{35}$. The disappearance of the band $(\mathrm{C}=\mathrm{C}$ bond) in the magnetocaloric composite samples indicated the complete polymerization of the acrylic resin, showing that the incorporation $\mathrm{Gd}_{5.09} \mathrm{Ge}_{2.03} \mathrm{Si}_{1.88}$ as-cast compound does not affect the cure process of the acrylic resin. Also, the bands 840 and $747 \mathrm{~cm}^{-1}$ are attributed to the deformation vibrations of O-C-O of PMMA and stretching vibration of PMMA chains, respectively ${ }^{36,37}$. It's already known that resin containing filler disturbs the monomeric conversion of the composites, thus affecting some mechanical and optical properties $^{38-41}$.

\subsection{Thermogravimetricanalysis}

To investigate the thermal stability of the magnetocaloric composite, as well the extent of interaction between $\mathrm{Gd}_{5.09} \mathrm{Ge}_{2.03} \mathrm{Si}_{1.88}$ as-cast compound and PMMA, the thermal degradations of different samples MC (5, 7 and 10), the control sample and $\mathrm{Gd}_{5.09} \mathrm{Ge}_{2.03} \mathrm{Si}_{1.88}$ powder are presented in Figure 2. The weight loss for PMMA (control sample) due to release of absorbed water starts at $30^{\circ} \mathrm{C}$, continuing up to $145^{\circ} \mathrm{C}^{34}$. The polymer degradation starts at $180^{\circ} \mathrm{C}$. The breakage of the main polymer chain is verified above $300^{\circ} \mathrm{C}$, and is completed a slightly below $400^{\circ} \mathrm{C}$, with the highest degradation rate found around $370^{\circ} \mathrm{C}$. These values are in agreement with the observed in the literature ${ }^{36,42-45}$. In the thermogravimetric curve for the magnetocaloric composites, it is possible to notice that MC5 and MC7 samples had similar compositions, since they presented $84.8 \%$ and $85.4 \%$ of residue, respectively. These results indicated that both samples had a percentage of resin close to $15 \% \mathrm{w} / \mathrm{w}$, while MC10 presented about $18 \%$ of resin. The increasing in weight at $400^{\circ} \mathrm{C}$ for the magnetocaloric composites, as well as the $\mathrm{Gd}_{5.09} \mathrm{Ge}_{2.03} \mathrm{Si}_{1.88}$ powder, is due to the formation of germanium nitride which is a result of the continuous

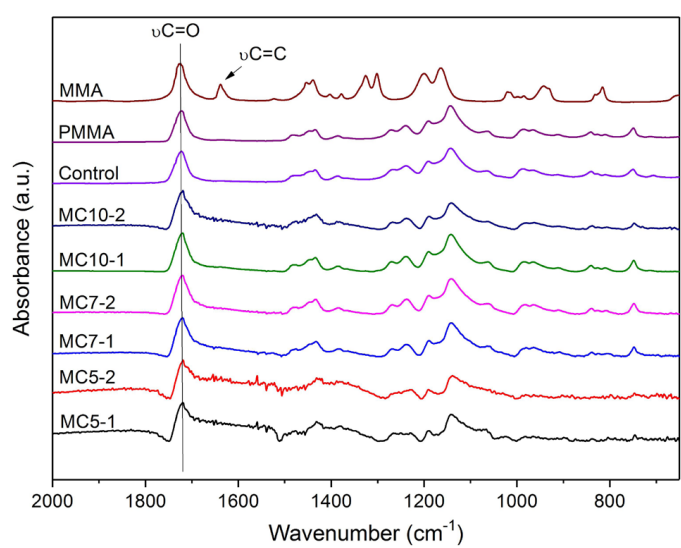

Figure 1. FTIR spectra of MMA, PMMA, Control, MC5, MC7 and $\mathrm{MC} 10$.

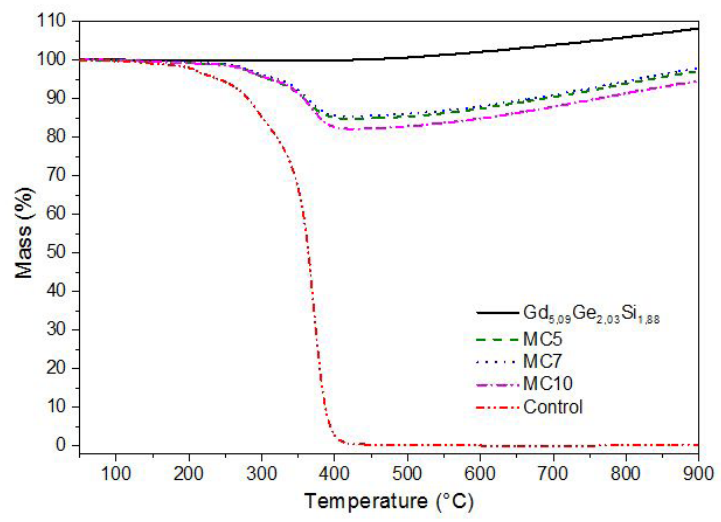

Figure 2. Thermogravimetric curve of $\mathrm{Gd}_{5.09} \mathrm{Ge}_{2.03} \mathrm{Si}_{1.88}$ powder, MC5, MC7, MC10 and Control.

nitrogen flow during the analyzes as presented in literature for nitride formation in other materials ${ }^{44}$. According to the TGA, the incorporation of a dispersed phase in the PMMA matrix improved the thermal stability of the polymer.

\subsection{Scanning electron microscopy}

The SEM images in Figure 3 showed the metallic particles (filler) with shapes and sizes different amongst the composites. The powder appearswell dispersed inside the composites, especially for the sample MC10. Furthermore, the adhesion of the matrix to the powder reinforcement is better at larger concentrations of polymer. Besides, it can be seen that the filler and matrix had good interactions with themselves as they presented no gaps between the powder and the polymer ${ }^{46}$. Even though, the smallest amount of PMMA in the samples MC5 and MC7 consequently lowered the contact area of the powder with the matrix,which can inducedifferent results on mechanical properties such as hardness and elastic modulus as it will be discussedlater. The irregular surface observed in the SEM images is due to the intergranular fracture of the composite.

\subsection{Vickers hardness}

Figure 4 shows the results of the Vickers hardness test. According to the analysis of variance, there was no statistical 

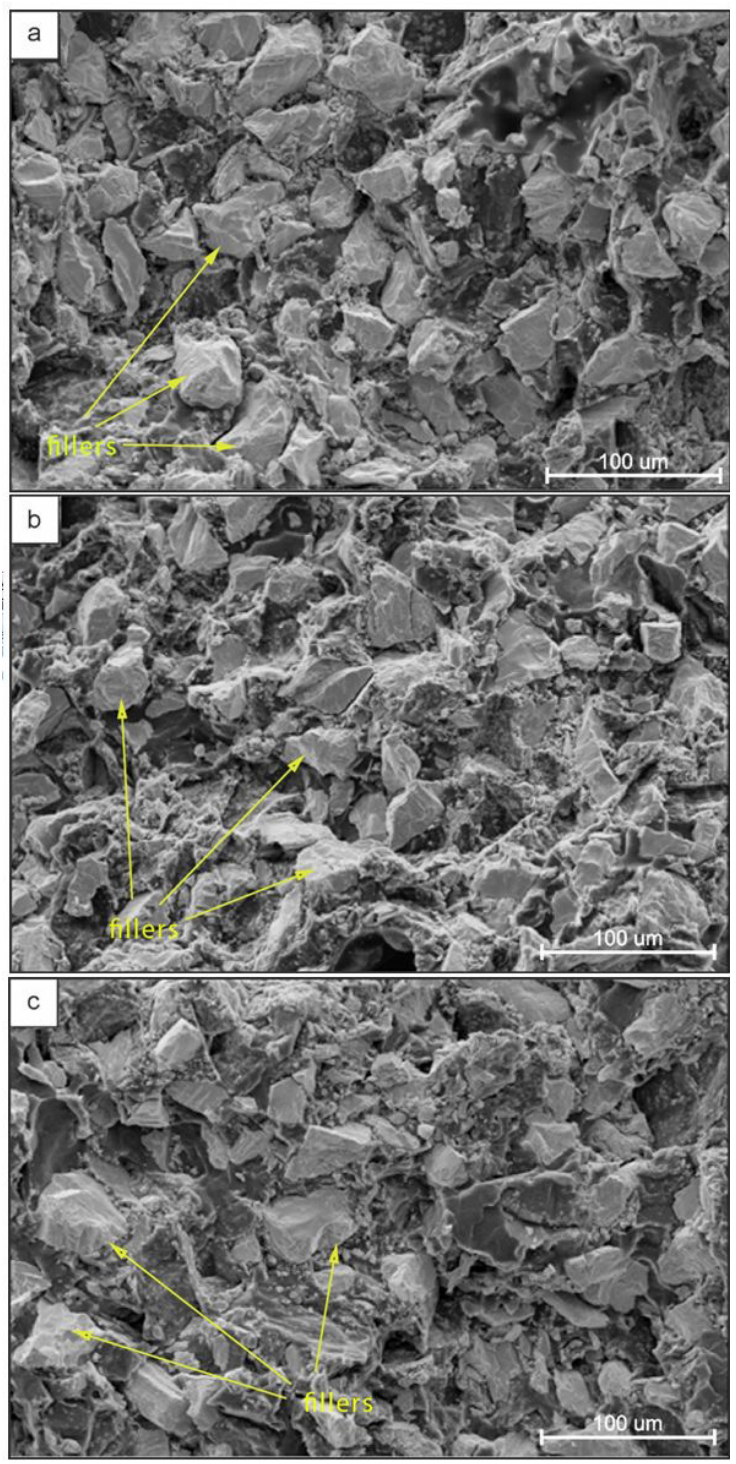

Figure 3. SEM micrographs of the (a) MC5, (b) MC7 and (c) MC10 samples.

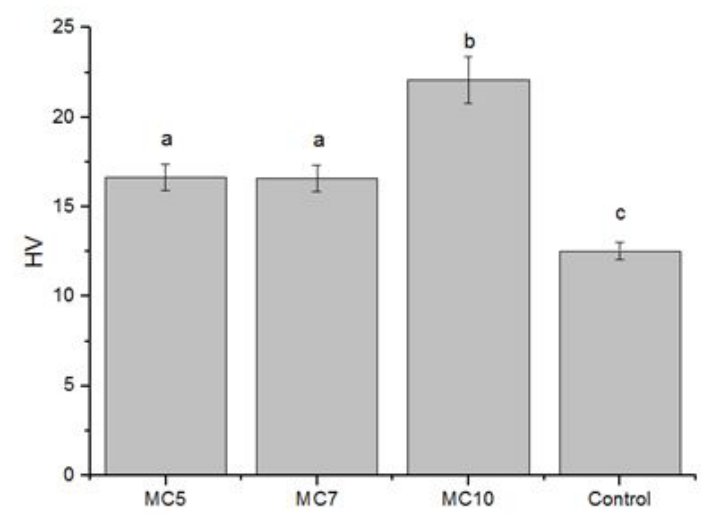

Figure 4. Vickers hardness of the magnetocaloric composites and control sample. Different letters indicate statistical differences between the samples.

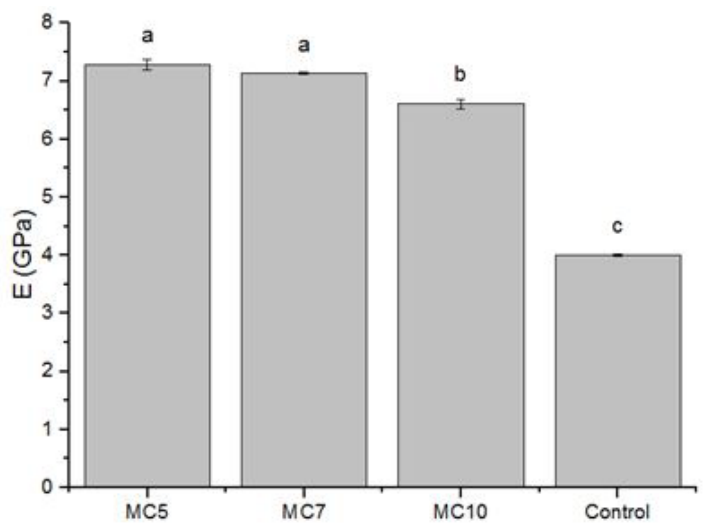

Figure 5. The elastic modulus of the magnetocaloric composites and control sample. Different letters indicate statistical differences between the samples.

difference between samples MC5 and MC7, which presented 16.66 and $16.59 \mathrm{HV}$, respectively, while MC10 presented a value of $22.10 \mathrm{HV}$. The hardness increase with reduction of reinforcement on the composites seems counterintuitive since the magnetocaloric powder is harder than the polymer matrix. However, this phenomenon can be explained by the better adhesion of the powder to the polymeric phase, as lower polymer concentration leads to aggregation of the powdered particles ${ }^{47,48}$. Thus, composites with high filler concentrations present this synergetic effect increasing the hardness value for these specific compositions ${ }^{47}$. The values of microhardness observed for the control sample, $12.54 \mathrm{HV}$, is lower than the found in the literature due to the longer time of indentation ${ }^{49,50}$.

\subsection{Elastic modulus}

Figure 5 shows the results of elastic modulus by impulse excitation of vibration. Again, according to ANOVA, there was no statistical differences between samples MC5 and MC7, which presented values of 7.29 and $7.13 \mathrm{GPa}$, respectively, while the MC10 and control samples showed statistically difference from other compositions, exhibiting lower values of 6.61 and $4.01 \mathrm{GPa}$, respectively. The measured elastic modulus of the control sample is close to that found in the literature ${ }^{47,48,51}$. On particle-reinforced composites, the dispersed phase restrains the movement of the matrix. This way, the reduction in the elastic modulus observed with the increase of polymer concentration is according to the expected and found in the literature ${ }^{47,48,52}$.

\subsection{Magnetic measurements and Magnetocaloric effect}

Magnetization as function of temperature ( $M v s . T)$ of the $\mathrm{Gd}_{5.09} \mathrm{Ge}_{2.03} \mathrm{Si}_{1.88}$ powder and the composite samples are displayed in Figure 6. Measurements confirmed the presence of first- and second-order transitions ${ }^{29-31}$, which were not affected by the presence of polymer. The transition temperatures were not affected as well, remaining around $264 \mathrm{~K}$ for the first-order transition and $301 \mathrm{~K}$ for the secondorder transition.

Figure 7 compares the isothermal entropy change (or MCE) as a function of the temperature for the $\mathrm{Gd}_{5.09} \mathrm{Ge}_{2.03} \mathrm{Si}_{1.88}$ powder 

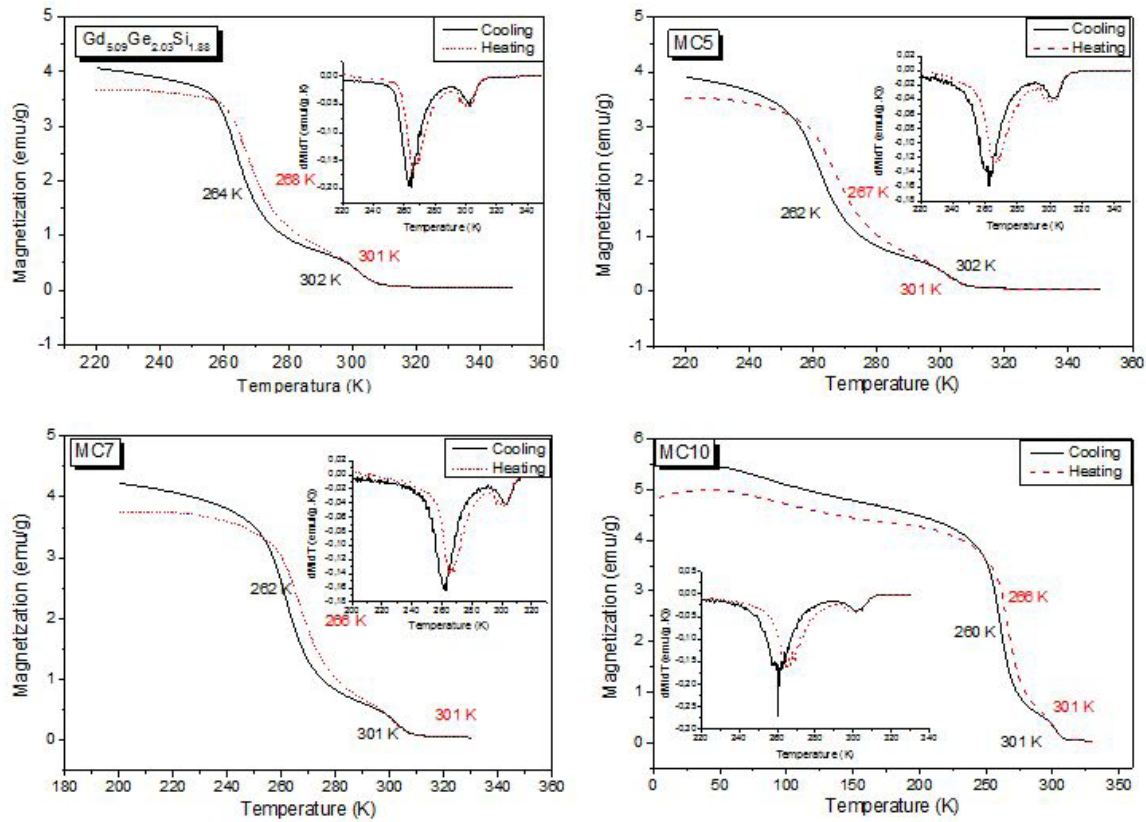

Figure 6. $M$ vs. $T$ measurements of $\mathrm{Gd}_{5.09} \mathrm{Ge}_{2.03} \mathrm{Si}_{1.88}$ powder, $\mathrm{MC} 5, \mathrm{MC} 7$ and $\mathrm{MC1}$. The insets on the graphs are the derivatives of the curves.

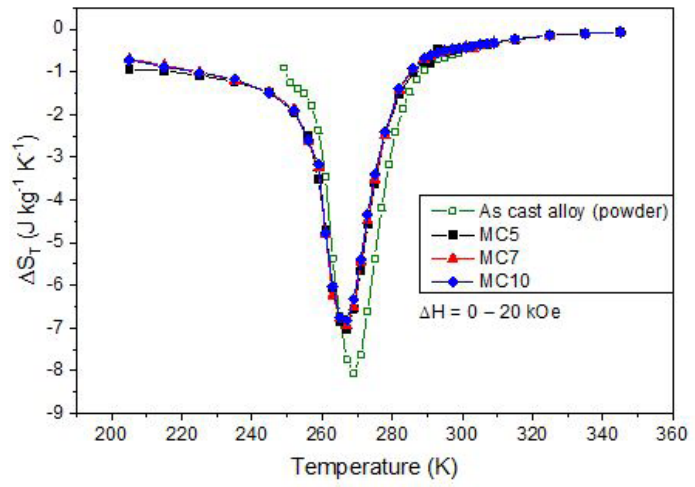

Figure 7. Isothermal variation of entropy $\left(\Delta \mathrm{S}_{\mathrm{T}}\right)$ at a magnetic field variation from 0 to $20 \mathrm{kOe}$ for $\mathrm{Gd}_{5.09} \mathrm{Ge}_{2.03} \mathrm{Si}_{1.88}$ powder, MC5, $\mathrm{MC} 7$ and MC10.

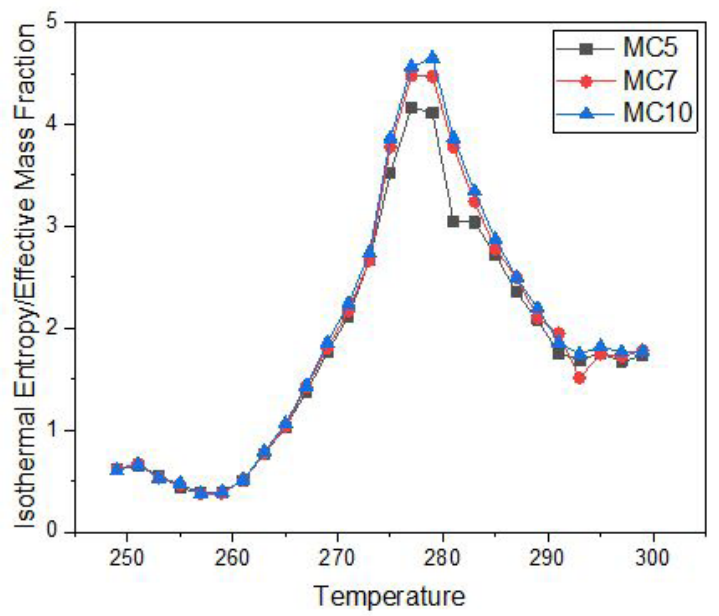

Figura 8. Effective PMMA mass fraction influence on the isothermal variation entropy $\left[\Delta \mathrm{S}_{\mathrm{T}} / \mathrm{PMMA}(\mathrm{g})\right]$ for various compositions. and the composites, under a magnetic field variation of $2 \mathrm{~T}$. The $\mathrm{Gd}_{5.09} \mathrm{Ge}_{2.03} \mathrm{Si}_{1.88}$ powder presented a "peak" $\mathrm{MCE}$ of $-8 \mathrm{~J} / \mathrm{kgK}$, which is close to the values reported in the literature ${ }^{20,29-31}$, for the same field variation. All three composites presented virtually the same curve of $\Delta \mathrm{S}_{\mathrm{T}} \mathrm{VS}$. $\mathrm{T}$, because, as presented in the TGA results, all the samples have almost the same PMMA concentration $(15-18 \%)$. The "peak" was slightly lower than the as-cast compound, around $-7 \mathrm{~J} / \mathrm{kgK}$. The small reduction on the MCE can be attributed to the presence of the polymer. However, thecomposites still present a satisfactory MCE.

Figure 8 shows the variation of isothermal entropy as a function of the effective polymer mass present in each prepared composite. The polymer masses used in this graph are measured by the TGA technique (Figure 2). As expected, the entropy variation is smaller the greater the amount of PMMA mass mixed with the metallic powder. Even so, when comparing the maximum values (around $\mathrm{T}=275 \mathrm{~K}$ ) of this variation of relative entropy for the samples with MC5 and MC10, it is observed that the decrease in the intensity of the effect is relatively small (about $20 \%$ ), whereas one has twice the amount of polymer by mass as the other.

\section{Conclusion}

The composite studied uses PMMA as matrix and the magnetocaloric material $\mathrm{Gd}_{5.09} \mathrm{Ge}_{2.03} \mathrm{Si}_{1.88}$ as particle reinforcement. TGA analysis showed that the manufactured samples had between $15 \%$ and $18 \%$ of polymer, different from the proposed, indicating no interpretations based on concentration. However, SEM images showed good homogeneity of the composites, especially for MC10, which presented the better distribution of the powder in the PMMA matrix.

In terms of mechanical properties, the analysis of elastic modulus and Vickers hardness, MC5, MC7 and MC10 presented, respectively, $7.29 \pm 0.09 \mathrm{GPa}$ and $16.66 \pm 0.73 \mathrm{HV}$, and 
$7.13 \pm 0.02 \mathrm{GPa}$ and $16.59 \pm 0.72 \mathrm{HV}$, and $6.61 \pm 0.08 \mathrm{GPa}$ and $22.10 \pm 1.29 \mathrm{HV}$. The higher hardness values observed for $\mathrm{MC} 10$ can be attributed to the lower presence of void spaces.

Finally, the $\Delta \mathrm{S}_{\mathrm{T}}$ calculated for the composites showed a small reduction of the MCE in comparison with the as-cast powder, without variation on the temperature transition of the magnetocaloric material. The results indicate that the PMMA based composite of this work is a promising route for first-order magnetocaloric materials to be applied as active magnetic regenerator, where mechanical stability and high MCE are fundamental properties towards the development of highly efficient magnetocaloric heat pumps.

\section{Acknowledgment}

The authors would like to acknowledge to Complex of Research Support Centers (COMCAP) for structural analysis, Araucaria Research Foundation of Paraná State, Coordination for the Improvement of Higher Education Personnel (CAPES), and Brazil's National Council of Scientific and Technological Development (CNPq) for the scholarship concession and financial support.

\section{References}

1. Pecharsky VK, Gschneidner KA Jr. Giant magnetocaloric effect in $\mathrm{Gd}_{5}\left(\mathrm{Si}_{2} \mathrm{Ge}_{2}\right)$. Phys Rev Lett. 1997;78(23):4494-7. http:// dx.doi.org/10.1103/PhysRevLett.78.4494.

2. Pecharsky AO, Gschneidner KA Jr, Pecharsky VK. The giant magnetocaloric effect of optimally prepared $\mathrm{Gd}_{5} \mathrm{Si}_{2} \mathrm{Ge}_{2}$. J Appl Phys. 2003;93(8):4722-8. http://dx.doi.org/10.1063/1.1558210.

3. Franco V, Blázquez JS, Ingale B, Conde A. The magnetocaloric effect and magnetic refrigeration near room temperature: materials and models. Annu Rev Mater Res. 2012;42(1):305-42. http:// dx.doi.org/10.1146/annurev-matsci-062910-100356.

4. Tishin AM, Spichkin YI. Recent progress in magnetocaloric effect: mechanisms and potential applications. Int J Refrig. 2014;37:223-9. http://dx.doi.org/10.1016/j.ijrefrig.2013.09.012.

5. Gschneidner KA Jr, Pecharsky VK. Thirty years of near room temperature magnetic cooling: where we are today and future prospects. Int J Refrig. 2008;31(6):945-61. http://dx.doi. org/10.1016/j.jirefrig.2008.01.004.

6. Brück E. Developments in magnetocaloric refrigeration. J Phys D Appl Phys. 2005;38(23):R381-91. http://dx.doi. org/10.1088/0022-3727/38/23/R01.

7. Pires MJM, Carvalho AMG, Gama S, da Silva EC, Coelho AA, Mansanares AM. Electron spin resonance and magnetic characterization of the Gd 5.09 Ge 2.03 Si 1.88. Phys Rev B Condens Matter Mater Phys. 2005;72(22):224435. http://dx.doi. org/10.1103/PhysRevB.72.224435.

8. Franco V, Blázquez JS, Ipus JJ, Law JY, Moreno-Ramírez LM, Conde A. Magnetocaloric effect: from materials research to refrigeration devices. Prog Mater Sci. 2018;93:112-232. http:// dx.doi.org/10.1016/j.pmatsci.2017.10.005.

9. Greco A, Aprea C, Maiorino A, Masselli C. A review of the state of the art of solid-state caloric cooling processes at roomtemperature before 2019. Int J Refrig. 2019;106:66-88. http:// dx.doi.org/10.1016/j.ijrefrig.2019.06.034.

10. Reis MS. Magnetocaloric and barocaloric effects of metal complexes for solid state cooling: review, trends and perspectives. Coord Chem Rev. 2020;417:213357. http://dx.doi.org/10.1016/j. ccr.2020.213357.

11. Smith A, Bahl CRH, Bjork R, Engelbrecht K, Nielsen KK, Pryds N. Materials challenges for high performance magnetocaloric refrigeration devices. Adv Energy Mater. 2012;2(11):1288-318. http://dx.doi.org/10.1002/aenm.201200167.
12. Gottschall T, Skokov KP, Fries M, Taubel A, Radulov I, Scheibel F, et al. Making a cool choice: the materials library of magnetic refrigeration. Advanced Energy Materials. 2019;9(34):1901322.

13. Barclay JA, Steyert WA. Active magnetic regenerator. United States patent USPatent 4332135. 1981.

14. KitanovskiA, TušekJ, TomcU, PlaznikU, OžboltM, PoredošA. Green energy and technology. Switzerland: Springer International Publishing; 2014.

15. Trevizoli PV, Christiaanse TV, Govindappa P, Niknia I, Teyber R, Barbosa JR Jr, et al. Magnetic heat pumps: an overview of design principles and challenges. Sci. Technol. Built Environ. 2016;22(5):507-19. http://dx.doi.org/10.1080/23744731.2016 .1171632 .

16. Jia P, Duan LP, Wang K, Wang EG. Magnetic properties and magnetocaloric effects of $\mathrm{Gd} 65(\mathrm{Cu}, \mathrm{Co}, \mathrm{Mn}) 35$ amorphous ribbons. J Mater Sci Technol. 2019;35(10):2283-7. http:// dx.doi.org/10.1016/j.jmst.2019.05.056.

17. Trevizoli PV, Alves CS, Mendes MAB, Carvalho AMG, Gama S. Powder metallurgy influences on the magnetic properties of Gd5.09Ge2.03Si1.88 alloy. J Magn Magn Mater. 2008;320(8):15825. http://dx.doi.org/10.1016/j.jmmm.2008.01.007.

18. Provenzano V, Shapiro AJ, Shull RD. Erratum: reduction of hysteresis losses in the magnetic refrigerant $\mathrm{Gd}_{5} \mathrm{Ge}_{2} \mathrm{Si}_{2}$ by the addition of iron. Nature. 2004;429:853-857. http://dx.doi. org/10.1038/nature03683.

19. Thanh TD, Duc NH, Dan NH, Mai NT, Phan TL, Oh SK, et al. Magnetic and magnetocaloric properties of Ni-Ag-Mn-Sn ribbons and their composites. J Alloys Compd. 2017;696:112938. http://dx.doi.org/10.1016/j.jallcom.2016.12.102.

20. Tian HC, Zhong XC, Liu ZW, Zheng ZG, Min JX. Achieving table-like magnetocaloric effect and large refrigerant capacity around room temperature in Fe 78- $\mathrm{xCexSi4Nb5B12Cu1} \mathrm{(x=0-10)}$ composite materials. Mater Lett. 2015;138:64-6. http://dx.doi. org/10.1016/j.matlet.2014.09.127.

21. Radulov IA, Skokov KP, Karpenkov DY, Gottschall T, Gutfleisch O. On the preparation of $\mathrm{La}(\mathrm{Fe}, \mathrm{Mn}, \mathrm{Si}) 13 \mathrm{H}$ polymer-composites with optimized magnetocaloric properties. J Magn Magn Mater. 2015;396:228-36. http://dx.doi.org/10.1016/j.jmmm.2015.08.044.

22. Zhang H, Sun Y, Niu E, Hu F, Sun J, Shen B. Enhanced mechanical properties and large magnetocaloric effects in bonded $\mathrm{La}(\mathrm{Fe}$, $\mathrm{Si}{ }_{13}$-based magnetic refrigeration materials. Appl Phys Lett. 2014;104(6):062407. http://dx.doi.org/10.1063/1.4865236.

23. Zhang H, Sun Y, Li Y, Wu Y, Long Y, Shen J, et al. Mechanical properties and magnetocaloric effects in $\mathrm{La}(\mathrm{Fe}, \mathrm{Si})_{13}$ hydrides bonded with different epoxy resins. J Appl Phys. 2015;117(6):063902. http://dx.doi.org/10.1063/1.4908018.

24. Pulko B, Tušek J, Moore JD, Weise B, Skokov K, Mityashkin $\mathrm{O}$, et al. Epoxy-bonded La-Fe-Co-Si magnetocaloric plates. J Magn Magn Mater. 2015;375:65-73. http://dx.doi.org/10.1016/j. jmmm.2014.08.074.

25. Lanzarini J, Barriere T, Sahli M, Gelin JC, Dubrez A, Mayer $\mathrm{C}$, et al. Thermoplastic filled with magnetocaloric powder. Mater Des. 2015;87:1022-9. http://dx.doi.org/10.1016/j. matdes.2015.08.057.

26. Lazouzi GA, Vuksanovic MM, Tomic N, Petrovic M, Spasojevic P, Radojevic V, et al. Dimethyl itaconate modified PMMA alumina fillers composites with improved mechanical properties. J Polym Compos. 2019;40(5):1691-701. http://dx.doi.org/10.1002/ pc. 24952.

27. Chen X, Xu T, Lei H, Tan L, Yang L. Multifunctional nano-ZnO/ PMMA composites with high transparency prepared by one-step in situ polymerization. Polym Compos. 2019;40(2):657-63. http://dx.doi.org/10.1002/pc.24705.

28. Liu J, Zhang M, Shao Y, Yan A. LaFe11.6 Si1.4/Cu magnetocaloric composites prepared by hot pressing. IEEE Transactions on Magnetics, 2015;51, 1-2. 
29. Pecharsky VK, Gschneidner KA Jr. Magnetocaloric effect from indirect measurements: magnetization and heat capacity. J Appl Phys. 1999;86(1):565-75. http://dx.doi.org/10.1063/1.370767.

30. Pecharsky AO, Gschneidner KA Jr, Pecharsky VK. The giant magnetocaloric effect of optimally prepared Gd5Si2Ge2. J Appl Phys. 2003;93(8):4722-8. http://dx.doi.org/10.1063/1.1558210.

31. Imamura W, Coelho AA, Kupfer VL, Carvalho AMG, Zago JG, Rinaldi AW, et al. A new type of magnetocaloric composite based on conductive polymer and magnetocaloric compound. J Magn Magn Mater. 2017;425:65-71. http://dx.doi.org/10.1016/j. jmmm.2016.10.120.

32. Zhang H, Liu J, Zhang M, Shao Y, Li Y, Yan A. LaFe11.6Si1.4Hy/ Sn magnetocaloric composites by hot pressing. Scr Mater. 2016;120:58-61. http://dx.doi.org/10.1016/j.scriptamat.2016.04.021.

33. ASTM International. E1876-09: Standard Test Method for Dynamic Young's Modulus, Shear Modulus, and Poisson's Ratio by Impulse Excitation of Vibration. West Conshohocken: ASTM International; 2009.

34. Solhi L, Atai M, Nodehi A, Imani M. Anovel dentin bonding system containing poly(methacrylic acid) grafted nanoclay: synthesis, characterization and properties. Dent Mater. 2012;28(10):1041-50. http://dx.doi.org/10.1016/j.dental.2012.06.004. PMid:22795491.

35. Atai M, Solhi L, Nodehi A, Mirabedini SM, Kasraei S, Akbari $\mathrm{K}$, et al. PMMA-grafted nanoclay as novel filler for dental adhesives. Dent Mater. 2009;25(3):339-47. http://dx.doi. org/10.1016/j.dental.2008.08.005. PMid:18829096.

36. Duan G, Zhang C, Li A, Yang X, Lu L, Wang X. Preparation and characterization of mesoporous zirconia made by using a poly (methyl methacrylate) template. Nanoscale Res Lett. 2008;3(3):118-22. http://dx.doi.org/10.1007/s11671-008-9123-7. PMid:21787437.

37. Benabid FZ, Zouai F, Douibi A, Benachour D. Spectroscopic study of poly(vinylidene fluoride)/Poly(methyl methacrylate) m(PVDF/PMMA) blend. J. Adv. Chem. Eng. 2015;5(4):1-4. http://dx.doi.org/10.4172/2090-4568.1000137.

38. Leprince JG, Hadis M, Shortall AC, Ferracane JL, Devaux J, Leloup G, et al. Photoinitiator type and applicability of exposure reciprocity law in filled and unfilled photoactive resins. Dent Mater. 2011;27(2):157-64. http://dx.doi.org/10.1016/j. dental.2010.09.011. PMid:21067803.

39. Fan Z, Gong F, Nguyen ST, Duong HM. Advanced multifunctional graphene aerogel-poly (methyl methacrylate) composites: experiments and modeling. Carbon. 2015;81:396-404.

40. Solhi L, Atai M, Nodehi A, Imani M, Ghaemi A, Khosravi K. Poly(acrylic acid) grafted montmorillonite as novel fillers for dental adhesives: synthesis, characterization and properties of the adhesive. Dent Mater. 2011;28(4):369-77. http://dx.doi. org/10.1016/j.dental.2011.11.010. PMid:22169675.
41. Radulov IA, Karpenkov DY, Skokov KP, Karpenkov AY, Braun T, Brabänder V, et al. Production and properties of metal-bonded $\mathrm{La}(\mathrm{Fe}, \mathrm{Mn}, \mathrm{Si}) 13 \mathrm{H}$ composite material. Acta Mater. 2017;127:38999. http://dx.doi.org/10.1016/j.actamat.2017.01.054.

42. Alvarado-Beltrán CG, Almaral-Sánchez JL, Ramírez-Bon R. Synthesis and properties of PMMA-ZrO2 organic-inorganic hybrid films. J Appl Polym Sci. 2015;132(44):42738.

43. Buga M-R, Zaharia C, Bălan M, Bressy C, Ziarelli F, Margaillan A. Surface modification of silk fibroin fibers with poly(methyl methacrylate) and poly(tributylsilyl methacrylate) via RAFT polymerization for marine antifouling applications. Mater Sci Eng C. 2015;51:233-41. http://dx.doi.org/10.1016/j. msec.2015.03.006.

44. Abdelrazek EM, Hezma AM, El-khodary A, Elzayat AM. Spectroscopic studies and thermal properties of PCL/PMMA biopolymer blend. J Basic Appl Sci. 2016;3:10-5.

45. Chen H, Chen Y, Liu Y, Fu L, Huang C, Llewellyn D. Over 1.0 $\mathrm{mm}$-long boron nitride nanotubes. Chemical Physics Letters. 463(1-3):130-3.

46. Hassan A, Salema AA, Ani FN, Bakar AA. A review on oil palm empty fruit bunch fiber-reinforced polymer composite materials. Polym Compos. 2010;31(12):2079-101. http://dx.doi. org/10.1002/pc.21006.

47. Jindal P, Sain M, Kumar N. Mechanical characterization of PMMA/MWCNT composites under static and dynamic loading conditions. Mater. Today Proc. 2015;2(4-5):1364-72. http:// dx.doi.org/10.1016/j.matpr.2015.07.055.

48. Abere DV, Oyatogun GM, Akinwole IE, Abioye AA, Rominiyi AL, Magnus I. Effects of Increasing Chitosan Nanofibre Volume Fraction on the Mechanical Property of Hydroxyapatite. American Journal of Materials Science and Engineering. 2017;5(1):6-16.

49. Karthick R, Sirisha P, Sankar MR. Mechanical and Tribological Properties of PMMA-Sea Shell based Biocomposite for Dental application. Procedia Mater Sci. 2014;6:1989-2000.

50. Alhareb AO, Akil HM, Ahmad ZA. Impact strength, fracture toughness and hardness improvement of PMMA denture base through addition of nitrile rubber/ceramic fillers. J for Dent Res. 2017;8:(1).26-34.

51. Zamfirova G, Gaydarov V, Faraguna F, Vidović E, Jukić A. Influence of carbon nanotubes functionalization on the mechanical properties of polymethacrylate nanocomposites. Colloids Surf A Physicochem Eng Asp. 2016;510:169-75. http://dx.doi.org/10.1016/j.colsurfa.2016.08.031.

52. Banks-Sills L, Shiber DG, Fourman V, Eliasi R, Shlayer A. Experimental determination of mechanical properties of PMMA reinforced with functionalized CNTs. Compos, Part B Eng. 2016;95:335-45. http://dx.doi.org/10.1016/j. compositesb.2016.04.015. 